\title{
Atratividade de Canaviais Paulistas Sob a Ótica da Teoria das Opções Reais ${ }^{1}$
}

\author{
Leonardo Botelho Zilio² e Roberto Arruda de Souza Lima ${ }^{3}$
}

Resumo: Na atividade canavieira paulista constatou-se prejuízo econômico entre as safras 2007/08 e 2011/12, fato que leva ao objetivo do presente estudo: responder por que estes produtores mantêm-se no fornecimento de cana-de-açúcar. Além da análise tradicional de viabilidade, o estudo incorporou à análise o uso da Teoria das Opções Reais, proposta que inclui no modelo de decisão a flexibilidade gerencial do investidor. Foram analisados dois projetos típicos de investimento em cana-de-açúcar nas regiões de Piracicaba e Sertãozinho. Considerando-se o método do fluxo de caixa descontado, obteve-se estimativas que apontam para a atratividade econômica do plantio de cana em ambas as regióes, haja vista a resposta positiva dos Valores Presentes Líquidos calculados. Tais evidências foram corroboradas quando da utilização da Teoria das Opções Reais, proposta que incorpora no modelo de decisão a flexibilidade gerencial do investidor. Ressaltam-se como principais parâmetros de impacto na viabilidade financeira de empreendimentos canavieiros o preço e a qualidade da cana-de-açúcar e a produtividade agrícola. Ações que visem ganhos de produtividade agrícola são apontadas como motivadoras de ganhos financeiros, enquanto que, em termos de políticas públicas, cita-se a possibilidade de ajustes no sistema de precificação da gasolina $C$ e na tributação dos derivados da cana-de-açúcar.

Palavras-chaves: Viabilidade econômica; Teoria das Opções Reais; Cana-de-açúcar.

Abstract: In the sugarcane production in Sao Paulo it was found that between crops 2007/08 and 2011/12 there was economic loss, a fact that leads to the goal of the present study: answer why these producers still remain providing sugarcane. Apart from the traditional viability analysis, the study incorporated the Real Options Theory analysis, which includes managerial flexibility on the investor decision model. Two sugarcane investment projects based on available information of Piracicaba and Sertãozinho regions

1. Data de submissão: 8 de fevereiro de 2014. Data de aceite: 8 de junho de 2015 .

2. Doutor em Economia Aplicada - Universidade de São Paulo, Escola Superior de Agricultura "Luiz de Queiroz" - USP/ESALQ. Piracicaba, São Paulo, Brasil. E-mail: leonardo.b.zilio@gmail.com

3. Professor Doutor do Departamento de Economia, Administração e Sociologia - Universidade de São Paulo, Escola Superior de Agricultura "Luiz de Queiroz" - USP/ESALQ. Piracicaba, São Paulo, Brasil. E-mail: raslima@usp.br 
were analyzed. Considering the discounted cash flow method, we obtained estimates pointing to the economic attractiveness of sugarcane planting in both regions, as shown by the positive response of the Net Present Values calculated. This evidence was corroborated when using the Real Options Theory, which incorporates flexibility on the decision model. Price and quality of sugarcane and agricultural productivity presented the higher impact on the financial viability of projects. Actions focused on agricultural productivity gains are seen as motivating for financial gain, while in terms of public policy we mention the possibility of adjustments in $C$ gasoline pricing systems and in the taxation on sugarcane byproducts.

Key-words: Economic viability; Real Option Theory; Sugarcane.

http://dx.doi.org/10.1590/1234-56781806-9479005303001

Classificação JEL: O22, G11.

\section{Introdução}

Após a inserção do automóvel bicombustível no mercado brasileiro, em 2003, o setor sucroenergético experimentou significativo crescimento. Entre as safras 2005/06 e 2009/10 foram inauguradas 103 novas usinas de açúcar e etanol, elevando a capacidade produtiva a patamares recordes. No entanto, como reflexo da crise mundial de 2008, observou-se uma diminuição natural no ritmo de investimentos voltados ao setor, seja na indústria, seja no campo (UNICA, 2012; PECEGE, 2011). Particularmente no que tange à etapa agrícola, vislumbrou-se, em 2011, quedas acentuadas de produtividade, as quais contribuíram para a diminuição da produção brasileira de cana de 625 milhões de toneladas na safra 2010/2011 para 555 milhões na safra 2011/2012. Além das questões climáticas envolvidas, a falta de investimentos nas reformas dos canaviais e no correto manejo da soqueira (tratos culturais) são apontados como fatores determinantes para tal queda de produção (UNICA, 2011; NEVES, 2011).

Levando-se em conta a realidade paulista, outros fatores vêm encarecendo os custos de produção canavieiros, tais como os elevados preços de terras e da mão de obra, o que compromete a atratividade da atividade no estado. Isto posto, conclui-se que a atividade canavieira paulista, no nível do fornecedor de cana, passa por um período delicado em termos de sustentabilidade econômica. Segundo Marques (2009), Xavier et al.
(2009) e Pecege $(2010,2011,2012)$, entre as safras 2007/2008 e 2011/2012 os custos totais de produção da cana-de-açúcar mantiveram-se em tal magnitude que os preços médios recebidos não foram suficientes para garantir o equilíbrio econômico. De acordo com estes autores, apenas em algumas regiões, como em Assis/SP, foram encontradas margens médias positivas no decorrer do período analisado. Conclui-se que possivelmente o típico fornecedor de cana-de-açúcar paulista possa ter como comprometida a atratividade de sua atividade no longo prazo. Cabe, então, uma série de questionamentos, tais como: i) por que os fornecedores de cana mantêm-se na atividade? ii) qual o movimento produtivo esperado desses fornecedores a partir de então, ou seja, qual o destino das terras atualmente utilizadas na produção de cana (venda, arrendamento ou permanência do fornecimento de matéria-prima à usina)? iii) o que de fato impacta na atratividade da atividade e quais variáveis podem ser controladas a fim de se elevar a rentabilidade? iv) estariam esses fornecedores valorando de forma diferente sua realidade econômica, tal como mantendo viva uma opção de aguardar maiores informações de preços e custos para, então, definir o rumo de sua atividade?

Objetiva-se, dessa forma, estimar a atratividade econômica da produção de cana-de-açúcar tomando como base a realidade de duas regiões do estado de São Paulo: Piracicaba e Sertãozinho. Adicionalmente, deseja-se mensurar o valor da 
opção de prosseguir na atividade produtiva da cana-de-açúcar, comparando os resultados obtidos via utilização da Teoria das Opções Reais (TOR) com aqueles obtidos através das análises convencionais de investimento.

\section{Revisão de literatura}

\subsection{Histórico recente do setor sucroenergético brasileiro}

Em 2003, o advento dos veículos bicombustíveis fez com que a demanda por etanol crescesse vertiginosamente, levando a significativos investimentos na construção de novas destilarias e fábricas de açúcar em todo o Centro-Sul brasileiro. Observou-se grande crescimento na produção de cana-de-açúcar até a safra 2010/11, que foi interrompido na safra 2011/12 em virtude de questões climáticas e da cumulativa falta de investimentos em reforma dos canaviais (PECEGE, 2012; UNICA, 2012). A partir de 2008, em grande parte devido aos efeitos da crise mundial ocorrida no mesmo ano, verifica-se uma redução no número de novas usinas, bem como nos investimentos em renovação de canaviais em todo o Brasil. Consequência disso e devido às condições climáticas desfavoráveis foi a severa queda na produtividade agrícola constatada principalmente na safra 2011/12, na qual os níveis históricos de 85 toneladas de cana (tc)/hectare (ha) deram lugar a valores na faixa de $70 \mathrm{tc} / \mathrm{ha}$ no Centro-Sul, um dos piores desempenhos da década de 2000 (UNICA, 2011; PECEGE, 2011). Nos períodos mais recentes nota-se uma tentativa de reestruturação do setor, seja por parte das unidades industriais, as quais direcionam os bons resultados financeiros obtidos nas safras 2010/11 e 2011/12 à reforma dos canaviais; seja por parte do governo, que lançou em janeiro de 2012 a linha de crédito Prorenova. Esta linha, lançada num montante de R\$ 4 bilhões, tem como intuito financiar pessoas físicas e jurídicas que possuam investimentos no setor sucroenergético via plantio de cana-de-açúcar, tanto para formação quanto para renovação de canaviais. Tendo como órgão executor o Banco Nacional de Desenvolvimento Econômico e Social (BNDES), libera até R\$ 4.350,00/ha e possui flexibilidade quanto ao prazo de pagamento.

Por fim, cabe salientar que a participação do fornecedor na produção total de cana-de-açúcar vem caindo ao longo das últimas três décadas. Conforme mostra a Figura 1, ao longo dos anos 1980 os fornecedores respondiam por patamares entre $30 \%$ e $35 \%$ do total da cana moída no Centro-Sul brasileiro, ao passo que três décadas mais tarde, na safra 2011/12, esse percentual caiu para aproximadamente 25\% (UDOP, 2012; ORPLANA, 2012b; UNICA, 2012, 2013).

Figura 1. Participação de fornecedores na produção total de cana-de-açúcar no Centro-Sul brasileiro: safras 1984/85 a 2011/12

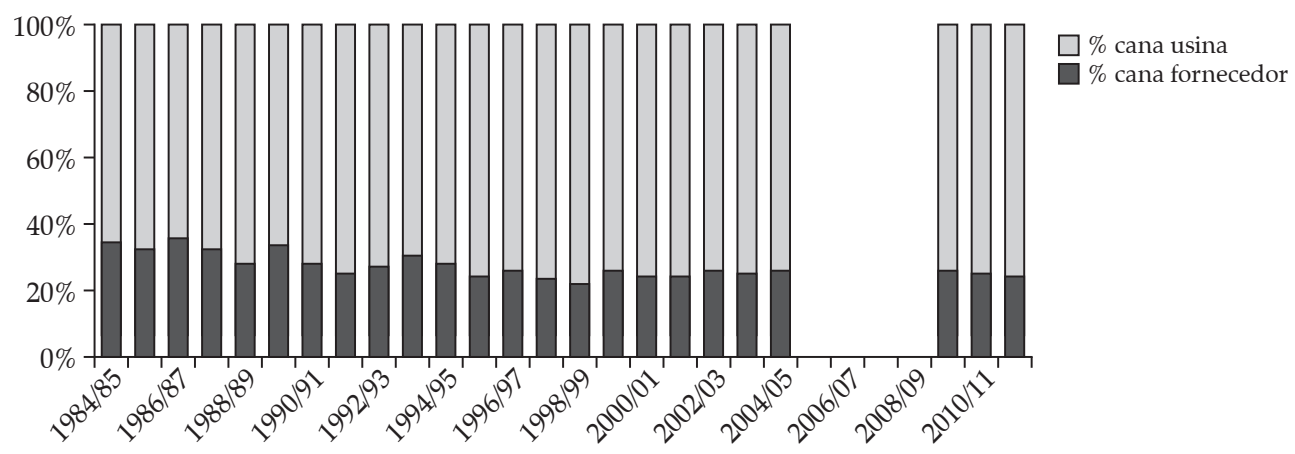

Nota: Dados indisponíveis para o período que compreende as safras 2005/06 a 2008/09.

Fonte: Udop (2012), Orplana (2012b), Unica (2012, 2013). 


\subsection{Métodos convencionais de análise de projetos}

A aplicação de métodos tradicionais de análise de projetos de investimento, em particular os do Valor Presente Líquido (VPL) e da Taxa Interna de Retorno (TIR), é bastante difundida, inclusive na agroindústria brasileira. Kaneko et al. (2009) e Zilio (2012) chegam a conclusões semelhantes quanto à viabilidade econômica da produção canavieira no estado de São Paulo. Kaneko et al. (2009) desenvolvem um estudo de caso para uma pequena propriedade localizada no município de Sud Mennucci/SP. Segundo os resultados do VPL (- R\$ 278,48) e da TIR $(2,54 \%)$, o fornecimento de cana-de-açúcar do produtor que terceiriza $100 \%$ de suas operações agrícolas não é alternativa interessante para a região. Zilio (2012) analisou a atratividade econômica do setor canavieiro brasileiro, levando em consideração a realidade produtiva de fornecedores de cana-de-açúcar nas regiões Tradicional e de Expansão de cana no Brasil ${ }^{4}$. A conclusão é que, segundo os métodos tradicionais VPL e TIR, na primeira região vislumbra-se inviabilidade econômica, com VPL de - R\$ 400 mil e TIR de $5,89 \%$, enquanto que na segunda região vê-se um cenário atrativo, com VPL de R\$ 1,98 milhão e TIR de 12,55\%. O fator risco do projeto não foi explorado pelo autor.

Percebe-se que os riscos intrínsecos à produção agrícola não são adequadamente mensurados em diversos estudos. As respostas deduzidas dos indicadores tradicionais de atratividade dão subsídios admissíveis para a tomada de decisão do investidor, mas falham por se tratarem de medidas puramente determinísticas, deixando as probabilidades de ocorrência de sucesso e fracasso omitidas das análises. Dadas as limitações existentes na teoria tradicional de análise de projetos, autores como Dixit e Pindyck (1994), Trigeorgis (1996) e Copeland e Tufano (2004) propõem o uso de técnicas mais apuradas para análise de portfólios de investimentos, tais como o método da Teoria das Opções Reais.

4. A definição dos conceitos de região Tradicional e de Expansão é amplamente abordada por Marques (2009), Xavier et al. (2009) e Pecege (2010, 2011, 2012).

\subsection{Sobre a Teoria das Opções Reais (TOR)}

A teoria convencional que trata das decisões de investimentos, na maioria dos casos, entende como atrativo um investimento no qual o valor presente das receitas futuras supera o valor presente dos custos envolvidos no respectivo processo. Nesses casos, as decisões de aceitação ou não de um empreendimento são indicadas sob uma perspectiva de "agora ou nunca", em $t=0$, não sendo possível mensurar qual seria o valor do projeto caso a decisão fosse tomada em outro instante do tempo. Contudo, em geral existe a possibilidade de o empreendedor aguardar $n$ períodos para que, contando com novas informações, tome a melhor decisão sobre a execução do projeto. Nesse sentido, esse empreendedor possui o equivalente ao que seria uma opção financeira de compra (call), na qual ele possui o direito, mas não a obrigação, de investir quando lhe for conveniente (COPELAND e TUFANO, 2004). Neste caso, a regra do VPL deve ser modificada, uma vez que o investimento só será atrativo se o valor presente dos fluxos de caixa projetados for maior ou igual ao somatório do investimento inicial mais o custo de oportunidade de manter essa call ativa (DIXIT e PINDYCK, 1994). Segundo estes autores, tal custo de oportunidade, desconsiderado nas análises tradicionais, é de substancial importância na tomada de decisão de investimentos.

Brasil et al. (2011) sustentam o fato de que "a implementação de um modelo baseado em opções reais inicia pela determinação do valor do ativo subjacente". Comumente, utiliza-se o VPL estimado do investimento como preço do ativo na modelagem, pois acredita-se que esta seja a melhor alternativa de precificação disponível para o ativo em questão.

Trigeorgis (1996), Dixit e Pindyck (1994) e Celoto (2004) detalham as principais classes de opções intrínsecas a projetos físicos de investimentos, das quais destacam-se as opções de adiar, alterar a escala, abandonar, alternar o uso e aguardar a queda do custo de capital. Tais opções podem estar simultaneamente à disposição do investidor. Segundo Trigeorgis (1996), essa flexi- 
bilidade gerencial existente faz com que a curva do VPL tome formato assimétrico, diferente do tradicionalmente representado pela distribuição Normal de probabilidades. Isto ocorre porque, modelando o projeto com base na TOR, as decisões são tomadas de forma a maximizar os retornos do projeto nos $n$ instantes de tempo designados, e não apenas em $t=0$.

Kjærland (2007) adota os conceitos de opções reais para explorar resultados de potenciais investimentos em geração hidrelétrica na Noruega. O autor identifica que, a despeito dos persistentes aumentos de preços da eletricidade na primeira metade da década de 2000, os investimentos em hidroeletricidade mantiveram níveis baixos entre 1993 e 2004. No cenário-base proposto os resultados apontam para atratividade econômica da atividade, estimando um valor de EUR 1,4 milhão/ GWh em oportunidades de investimentos em geração hidroelétrica de pequena escala. Ademais, o "preço de gatilho" ótimo calculado foi de EUR 40/MWh, valor considerado historicamente alto pelo estudo. Segundo o autor, por este motivo, aliado ao fato de o investimento em análise ser irreversível e considerando-se os elevados níveis de volatilidade dos preços, os investimentos potenciais existentes tendem a ser executados apenas em períodos futuros, quando novas informações estiverem à disposição dos agentes envolvidos no setor energético norueguês.

Por outro lado, Madlener et al. (2005) e Kumbaroğlu et al. (2006) estudaram o setor de fornecimento de eletricidade turco, utilizando a TOR. No primeiro caso os autores desenvolvem um modelo de programação dinâmica para identificar a atratividade econômica da implantação de tecnologias de geração de eletricidade disponíveis. Suas conclusões deixam claro que a disseminação da tecnologia de queima de gás natural, apesar de limitar as emissões de poluentes, deu-se de forma contraditória em relação à perspectiva do investidor. Para eles, a alta volatilidade dos preços domésticos do gás natural reduz a atratividade do investimento. Kumbaroğlu et al. (2006), dando continuidade às análises de Madlener et al. (2005), desenvolveram um modelo baseado na TOR para prospecção e difusão de novas tecnologias renováveis de energia, também tomando como base o mercado turco. Os autores inserem em seu estudo informações de curvas de aprendizagem para as diferentes tecnologias atualmente disponíveis naquele mercado, tais como geração de eletricidade via "Turbinas a gás de ciclo combinado" e "Carvão" (denominadas fontes "sujas" de energia), e via fontes limpas, tais como "Nuclear", "Hidroelétrica" e "Eólica". Dentre as premissas adotadas pelo estudo, nota-se que as taxas de aprendizagem das fontes limpas são significativamente superiores às fontes sujas, uma vez que os custos unitários de investimentos e operação encontram-se em patamares superiores no primeiro caso. Assim, espera-se que ao longo dos anos tais custos convirjam para valores mais próximos àqueles observados na geração suja de energia.

Zilli (2010) propõe-se a estimar o valor de propriedades rurais nas regiões de Carazinho/RS e Cascavel/PR utilizando, complementarmente ao método do VPL, a TOR. O autor conclui que a flexibilidade gerencial de postergar a venda das terras gera valor adicional entre 50\% e 118\% com relação aos dados secundários considerados no estudo. Entretanto, quando comparados aos valores levantados junto a produtores rurais de ambas as regiões, nota-se que em Carazinho/RS existe comercialização de terras por valores superiores aqueles aferidos pelo modelo com base na TOR, enquanto que em Cascavel/PR esta relação é inversa. Isto leva o autor a concluir que, na primeira região, as terras estavam em patamares de preços supervalorizados, enquanto que, na segunda, elas estariam possivelmente sendo negociadas de forma subvalorizada.

\section{Metodologia}

\subsection{Caracterização da produção canavieira típica das regiões de Piracicaba e Sertãozinho}

Considerou-se no modelo proposto um fornecedor típico que entrega 6.500 toneladas de cana $(\mathrm{tc})$ por safra às usinas sucroenergéticas da 
região de Piracicaba, mantendo concordância com os pressupostos de Pecege (2012). De acordo com CTC (2012b), a produtividade agrícola média dos canaviais piracicabanos foi de 85,51 tc/ha, levando em consideração o período de 1998 a 2011. As análises consideraram, portanto, uma propriedade de 76 ha para o cultivo da cana-de-açúcar. Ainda de acordo com CTC (2012b), no mesmo período, a cana-de-açúcar da região de Piracicaba processada nas usinas locais caracterizou-se pelo teor médio de açúcares totais recuperáveis (ATR) de 140,10 kg/tc.

Segundo Marques (2009), Xavier et al. (2009) e Pecege (2010, 2011, 2012), estima-se que em Piracicaba e região $50 \%$ da produção dos fornecedores típicos seja realizada em áreas próprias e 50\% em terras arrendadas. Nos contratos de arrendamento do estado de São Paulo comumente estipula-se a quantidade fixa de $121,97 \mathrm{~kg}$ ATR/tc, que é o denominado ATR padrão para contratos de arrendamento. Ainda segundo os autores, na região de Piracicaba paga-se um preço físico médio de 16,70 tc/ha/ano nos arrendamentos firmados. O ciclo de produção canavieiro completa-se em seis anos, sendo necessário, após esse período, renovar o canavial.

Além disso, nota-se na mesma região uma distribuição relativamente homogênea quanto aos ambientes de produção edafoclimáticos, uma vez que $48 \%$ das terras piracicabanas podem ser classificadas dentro dos ambientes de produção $\mathrm{A}$ e $\mathrm{B}$, sendo os $52 \%$ restantes classificadas nos ambientes C, D e E (CTC, 2012a).

Em relação à produção típica de Sertãozinho, considerou-se a premissa definida por Pecege (2012), que contempla um produtor que tipicamente entrega 15.000 toneladas de cana por safra como o mais representativo da região. Com base nesse valor e na premissa de produtividade agrícola média de 86,99 tc/ha (CTC, 2012b), estima-se que a área da propriedade típica da região de Sertãozinho alcance os 172,4 hectares. Ainda segundo CTC (2012b), o teor médio de ATR da cana-de-açúcar nessa região, considerando-se a série histórica entre 1998 e 2011, foi de 138,75 kg/tc.
Segundo Marques (2009), Xavier et al. (2009) e Pecege (2010, 2011, 2012), estima-se que em Sertãozinho a produção do fornecedor típico seja realizada na proporção de $100 \%$ de terras próprias e $0 \%$ de terras arrendadas. Assim como para a realidade piracicabana, os contratos de arrendamento baseiam-se na quantidade fixa de 121,97 $\mathrm{kg}$ ATR/tc, enquanto que o ciclo caracteriza-se por seis cortes seguidos da reforma do canavial. O preço físico médio dos contratos de arrendamentos foi considerado em 27,33 tc/ha/ano.

\subsection{Estrutura financeira típica das regiões de Piracicaba e Sertãozinho}

As despesas operacionais atribuídas aos projetos canavieiros dos fornecedores típicos das regiões de Piracicaba e Sertãozinho são apresentadas na Tabela 1. A valores monetários de 2012, considerando como deflator o IGP-DI, segundo Marques (2009), Xavier et al. (2009) e Pecege (2010, 2011, 2012), o custo operacional efetivo ${ }^{5}$ médio do cultivo de cana-de-açúcar nas regiões de Piracicaba e Sertãozinho é de R\$ 4.334,67/ha e de R \$ 4.725,63/ha, respectivamente, já inclusos os desembolsos com arrendamentos. Sob as premissas de utilização de terras próprias e arrendadas nas análises de cada um dos projetos, deve-se, complementarmente, deduzir-se das áreas próprias os valores alocados na conta arrendamentos, uma vez que, como é o caso da região de Sertãozinho, a produção padrão é realizada exclusivamente em terras próprias. A Tabela 2 apresenta a relação de tributos incidentes sobre a produção de cana-de-açúcar nas regiões de Piracicaba e de Sertãozinho.

A produção canavieira arca com basicamente duas classes de investimentos iniciais: aqueles voltados às aquisições de terras e aqueles voltados às aquisições do maquinário. No primeiro caso foram considerados os preços médios reais, a valo-

5. No custo operacional efetivo são considerados os desembolsos atrelados à lavoura, não sendo contempladas depreciações, pró labore ou custos de oportunidade do capital ou da terra. 
Tabela 1. Custo operacional efetivo de produção da cana-de-açúcar nas regiões de Piracicaba e Sertãozinho

\begin{tabular}{lccc}
\hline \multicolumn{1}{c}{ Estádio de produção } & Piracicaba & Sertãozinho & Fator ponderação \\
\hline R $\$ \mathbf{h} / \mathbf{h a}$ & 97,45 & 959,64 & $1 / 6$ \\
Preparo de solo & 878,45 & $2.777,99$ & $1 / 6$ \\
Plantio & $2.763,01$ & 505,22 & $1 / 6$ \\
Trato cultural cana planta & 482,24 & $1.243,65$ & $5 / 6$ \\
Trato cultural cana soca & 985,83 & $1.439,46$ & $6 / 6$ \\
Corte, carregamento e transporte & $1.835,35$ & 82,23 & $6 / 6$ \\
Administração & 96,11 & $1.460,42$ & $6 / 6$ \\
Arrendamento & 894,40 & $4.725,63$ & \\
MÉDIA PONDERADA & $4.334,67$ & & \\
\hline
\end{tabular}

Nota 1: Dados deflacionados pelo IGP-DI: base 2012.

Nota 2: $\mathrm{O}$ fator de ponderação refere-se à parcela da área total a qual os respectivos estágios de custos se aplicam. Por exemplo, os custos de preparo de solo, plantio e tratos culturais da cana planta aplicam-se a apenas $1 / 6$ da área total cultivada na plenitude do canavial. Por sua vez, os custos com tratos culturais da soqueira aplicam-se a 5/6 da área total, e os custos de colheita e administração devem ser considerados sobre toda a área cultivada.

Fonte: Adaptado de Marques (2009), Xavier et al. (2009) e Pecege (2010, 2011, 2012).

Tabela 2. Tributos incidentes sobre a produção canavieira nas regiões de Piracicaba e Sertãozinho

\begin{tabular}{cccc}
\hline Tributo & Piracicaba & Sertãozinho & Incidência \\
\hline Taxa associativa & $2,00 \%$ & $1,25 \%$ & Faturamento \\
Funrural & $2,30 \%$ & $2,30 \%$ & Faturamento \\
CNA & $0,1 \%+\mathrm{R} \$ 98,97$ & $0,1 \%+\mathrm{R} \$ 98,97$ & Faturamento \\
ITR & $0,07 \%$ & $0,07 \%$ & VTN \\
\hline
\end{tabular}

Nota: VTN = Valor da Terra Nua.

Fonte: Adaptado de Marques (2009), Xavier et al. (2009) e Pecege (2010, 2011, 2012), CNA (2012), Zilio (2012).

res monetários de 2012, do hectare comercializado entre 1996 e 2012, segundo IEA (2013). Tal instituição delimita ainda preços diferenciados para terras destinadas a culturas de primeira e de segunda ${ }^{6}$, os quais atingem, respectivamente, patamares médios de $\mathrm{R} \$ 15.805,94 /$ ha e $\mathrm{R} \$ 12.737,64 /$ ha na região de Piracicaba e de R $\$ 21.407,35 /$ ha e R $\$ 15.466,22 /$ ha na região de Sertãozinho. Atrelando os valores das culturas de primeira aos ambientes de produção $\mathrm{A}$ e B e das culturas de segunda aos ambientes C, D e E, de forma ponderada, tem-se um preço médio real de $\mathrm{R} \$ 14.199,45 /$ ha adquirido no projeto da região de Piracicaba e de R\$20.086,97/ha em Sertãozinho. No primeiro caso, onde $50 \%$ da área foi admitida como sendo própria e, portanto, passível de aquisição, estimou-se investimento de R\$ $539.681,93$, enquanto que, na segunda realidade,

6. A definição utilizada pelo IEA para terra de cultura de primeira e de segunda pode ser consultada em http://ciagri. iea.sp.gov.br/bancoiea/Precor_Sistema_Sobre.aspx?cod_ sis $=8$. onde a totalidade da área deve ser adquirida, estimou-se investimento em terras de $\mathrm{R} \$ 3.463 .668,23$.

Os investimentos considerados para aquisições de maquinários seguiram as premissas de Pecege (2012). A valores de 2012, assumiram-se desembolsos de $\mathrm{R} \$ 445.433,57$ no projeto piracicabano e de R\$ 486.893,27 no de Sertãozinho, distribuídos ao longo dos dois primeiros períodos dos projetos.

A receita do fornecedor de cana-de-açúcar é formada basicamente por dois parâmetros: o preço de mercado do ATR, expresso em reais por quilograma de ATR ( $\$$ /kg de ATR); e a quantidade de ATR existente em cada tonelada de cana entregue à usina, expresso em quilogramas de ATR por tonelada de cana ( $\mathrm{kg}$ ATR/tc). A multiplicação desses dois fatores resulta no preço da cana-de-açúcar, este, expresso em reais por tonelada de cana $(\mathrm{R} \$ / \mathrm{tc})$.

O preço médio real histórico do quilograma do ATR comercializado no estado de São Paulo entre as safras 1999/00 e 2012/13 foi de R \$ 0,4365/kg ATR, conforme mostra a Figura 2 (ORPLANA, 2012a). 
Figura 2. Evolução dos preços reais pagos pelo quilograma de ATR no estado de São Paulo safras 1999/00 a 2012/13

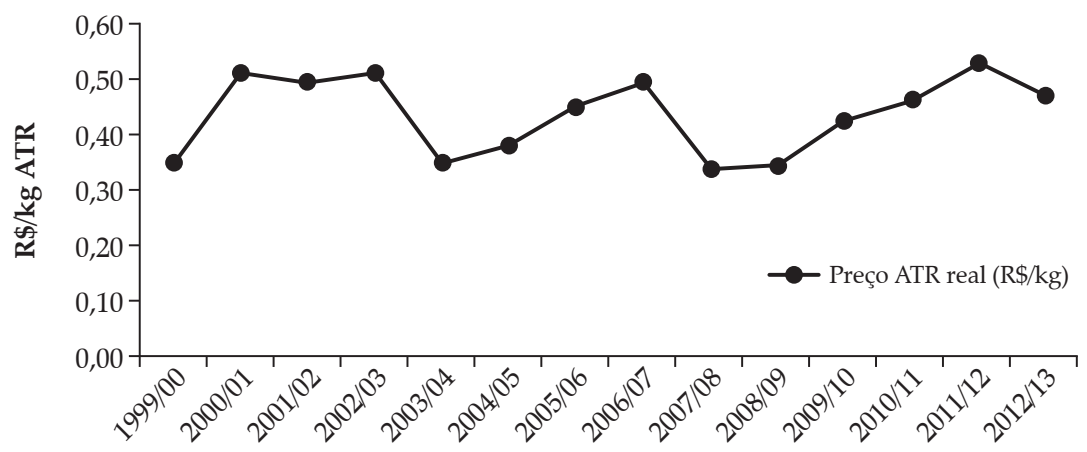

Nota: Dados deflacionados pelo IGP-DI: base 2012.

Fonte: Orplana (2012a).

Dessa forma, efetuando-se a multiplicação do preço do ATR pela respectiva quantidade de ATR por tonelada de cana, chega-se aos valores médios de R \$ 61,15/tc e R \$ 60,57/tc para os projetos das regiões de Piracicaba e Sertãozinho, respectivamente.

Com base em questionário estruturado aplicado a usinas da região de Sertãozinho ${ }^{7}$, constatou-se que tipicamente essas unidades industriais fornecem incentivos financeiros aos fornecedores de cana na etapa de Corte, Carregamento e Transporte (CCT), os quais variam de $10 \%$ a $44 \%$ do valor total do CCT. Em média, o modelo desenvolvido considerou um subsídio de $26 \%$ sobre o CCT, com duração ilimitada ao longo da vida útil do projeto. Não foram constatados incentivos semelhantes na região de Piracicaba.

7. Foram enviados questionários estruturados a oito grupos sucroenergéticos atuantes na região de Sertãozinho, cuja moagem totalizou, na safra 2010/2011, aproximadamente 59 milhões de toneladas de cana-de-açúcar. Foi perguntado aos respondentes se lhes eram dados incentivos aos fornecedores de cana; qual o regime de incidência (plantio, CCT etc.); qual o percentual de incentivo e por quanto tempo vigorava o incentivo. Foram obtidas respostas de três dos oito grupos sucroenergéticos consultados, que representam seis usinas.

\subsection{Valor Presente Líquido - VPL, Valor Uniforme Líquido - VUL e Taxa Interna de Retorno - TIR}

Para as estimações do VPL, do VUL e da TIR procedeu-se de acordo com Ross et al. (2007) e Perina (2007). Matematicamente, os indicadores podem ser expressos conforme as equações 1, 2 e 3 .

$$
\begin{aligned}
\mathrm{VPL} & =\mathrm{C}_{0}+\sum_{\mathrm{i}=1}^{\mathrm{T}} \frac{\mathrm{C}_{\mathrm{i}}}{(1+\mathrm{r})^{\mathrm{i}}} \\
\mathrm{VUL} & =\mathrm{VPL} \frac{\mathrm{r}(1+\mathrm{r})^{\mathrm{T}}}{(1+\mathrm{r})^{\mathrm{T}}-1} \\
\mathrm{VPL} & =\mathrm{C}_{0}+\sum_{\mathrm{i}=1}^{\mathrm{T}} \frac{\mathrm{C}_{\mathrm{i}}}{(1+\mathrm{TIR})^{\mathrm{i}}}=0
\end{aligned}
$$

Em que:

$C_{0}=$ fluxo de caixa inicial do projeto;

$C_{\mathrm{i}}=$ fluxo de caixa no período $i$, em que $i=\{1$,

$2, \ldots, T\}$;

$T=$ fim da vida útil do projeto;

$r=$ taxa de desconto ou TMA vinculada ao projeto;

Se as estimativas dos indicadores VPL e VUL forem maiores ou iguais a zero, então existem indícios que apontam para a aceitação do projeto. Caso contrário, o empreendimento deve ser recusado. Já a TIR deve ser comparada com a taxa mínima de atratividade (TMA) escolhida para 
análise. Se aquela taxa for maior ou igual à TMA, então o projeto apresenta viabilidade econômica. O mesmo será classificado como inviável se TIR $<$ TMA.

Dentre as restrições apontadas para o VPL e o VUL estão: i) a dependência da TMA, a qual possui intrinsecamente certo nível de subjetividade em sua determinação; ii) os resultados se tratam de valores absolutos e não relativos e iii) consideram a TMA constante ao longo do horizonte do projeto. Já em relação à TIR, salienta-se para os casos de projetos com múltiplas mudanças de sinal em seus fluxos de caixa líquidos (não convencionais), nos quais podem ser obtidas múltiplas TIR. Ademais, em análises de projetos de escalas não proporcionais pode-se estimar TIR discrepantes dos resultados obtidos via VPL. Ainda, como limitante comum a todos os métodos tradicionais abordados encontra-se o fato de que eles são determinísticos e inflexíveis, não sendo capazes de mensurar adequadamente os riscos e flexibilidades gerenciais intrínsecos a empreendimentos.

\subsection{Teoria das opções reais}

Copeland e Tufano (2004) defendem o modelo binomial dentre aqueles adequados para valoração de ativos via TOR, particularmente por se tratar de um método mais facilmente aplicável às decisões empíricas de investimentos.

A modelagem da árvore binomial, proposta que se utiliza de distribuições binomiais de probabilidades para estimar o preço de uma opção, parte do princípio básico de que o preço do ativo $\left(\mathrm{A}_{0}\right)$ em questão é conhecido em $t=0$. Deste ponto em diante, a trajetória de $\mathrm{A}_{0}$ só poderá tomar duas direções, tradicionalmente designadas como ascendente ou descendente, atingindo dois novos estados. Assim, em $t=1$ o preço do ativo pode assumir os valores $\mathrm{A}_{11}$ (tempo 1 , estado 1) ou $A_{12}$ (tempo 1, estado 2). Da mesma forma, em $t=1$ os estados $A_{11}$ e $A_{12}$ podem tomar duas direções, atingindo $\mathrm{A}_{21}, \mathrm{~A}_{22}, \mathrm{~A}_{23}$ ou $\mathrm{A}_{24}$ em $t=2$. Cada ponto $A_{t e}$ é denominado "nó", sendo que de cada nó originam-se duas novas possibilidades de trajetórias para o preço do ativo, caracterizando, assim, a chamada árvore binomial. Os passos são repetidos até $t=n$, sendo $n$ o prazo de maturação da opção ou, no caso de projetos de investimento, o horizonte do mesmo. Em $t=n$ existirão $2^{\mathrm{n}}$ nós finais. Assim, à medida que $n$ aumenta, o número de nós finais tende ao infinito, exigindo elevada capacidade operacional para que as estimativas desejadas sejam alcançadas. Para que o problema seja simplificado, deriva-se da árvore binomial a chamada rede binomial. A propagação da rede binomial se dá de forma semelhante à da árvore binomial, com a peculiaridade de que a cada novo passo os nós intermediários convergem de tal forma que alguns dos $A_{\text {te }}$ assumirão valores iguais. No passo $t=2$, por exemplo, $A_{22}=$ $A_{23}$. No período $t=3, A_{32}=A_{33}$ e $A_{34}=A_{35}$, e assim por diante. Nesse caso, em $t=n$ existirão exatamente $n+1$ possibilidades diferentes de preços para o ativo em questão.

Como $\mathrm{A}_{0}$ é conhecido, os valores $\mathrm{A}_{\mathrm{te}}$ subsequentes podem ser calculados multiplicando $A_{0}$ por um fator de alta $u$, no caso trajetória ascendente, e de baixa $d$, no caso de trajetória descendente. Dessa forma, tem-se que $A_{11}=A_{0} u$ e que $\mathrm{A}_{12}=\mathrm{A}_{0} d$. Posteriormente, ter-se-á que $\mathrm{A}_{21}=\mathrm{A}_{11} u$, $\mathrm{A}_{22}=\mathrm{A}_{23}=\mathrm{A}_{11} d=\mathrm{A}_{12} u$, e que $\mathrm{A}_{24}=\mathrm{A}_{12} d$, mantendo-se o mesmo padrão para os passos seguintes. Tem-se como condição necessária que $u>d$. Denota-se, ainda, que $u$ e $d$ decorrem de taxas de variações, podendo ser representados por:

$$
\begin{aligned}
& \mathrm{u}=1+\mathrm{i}_{\mathrm{u}} \\
& \mathrm{d}=1+\mathrm{i}_{\mathrm{d}}
\end{aligned}
$$

Em que $i_{\mathrm{u}}$ é a taxa de variação no caso de subida de preços e $i_{\mathrm{d}}$ é a taxa de variação no caso de queda de preços. Generalizando a rede binomial multiplicativa, partindo-se de $\mathrm{A}_{0}$ e considerando-se todas as possíveis subidas de preços, ter-se-ia, em $\mathrm{t}=n, d^{0} u^{\mathrm{n}} \mathrm{A}_{0}$. Por outro lado, caso fossem acompanhadas todas as possíveis quedas de preços se obteria $d^{\mathrm{n}} \mathbf{u}^{0} \mathrm{~A}_{0}$ em $\mathrm{t}=n$. Associadas a cada taxa de variação estão as respectivas probabilidades de ocorrência. Denota-se por $p$ a probabilidade de subida de preços, e por $(1-p)$ 
a probabilidade de queda. Assim, em cada nó o preço pode "caminhar para cima" com probabilidade $p$ ou "caminhar para baixo" com probabilidade $(1-p)$.

Por outro lado, pode-se desejar trabalhar com o modelo binomial aditivo, que leva em conta adição ou subtração de fatores constantes aos valores originais do ativo objeto analisado. Nesse caso, denominam-se $v$ e $\delta$ como parâmetros de subida e queda de preços, respectivamente. A Figura 3 ilustra a evolução da rede binomial no caso aditivo. Em geral, tem-se $\delta<0$, denotando perda de valor do ativo em análise.

As redes binomiais aditivas possuem a característica de possibilitarem a aferição de valores negativos para os preços dos ativos em análises, o que se mostra conveniente no caso de estudos que tratem como ativo físico o VPL de determinado projeto de investimento, por exemplo.

De posse da rede binomial para o ativo $A_{0}$, pode-se determinar o valor da opção nó a nó. Os procedimentos para o cálculo do valor da opção no período $t=0$ são distintos para as análises que consideram opções dos tipos europeia ou americana. No primeiro caso, parte-se dos valores resultantes de $\mathrm{A}_{0}$ em $t=n$, trabalhando-se de frente para trás no sentido de estimar os valores das opções nos nós precedentes, até que se chegue ao valor da opção em $t=0$. Já no caso da opção do tipo americana, a qual pode ser exercida em qualquer instante do tempo, o procedimento possui uma série de etapas adicionais. $\mathrm{O}$ primeiro passo será calcular o valor das opções nó a nó, obedecendo a equação (6).

$$
\mathrm{O}_{\mathrm{t}, \mathrm{e}}=\max \left(\mathrm{S}_{\mathrm{t}, \mathrm{e}}-\mathrm{K} ; 0\right)
$$

Em que:

$O_{\mathrm{t}, \mathrm{e}}=$ valor da opção no instante de tempo $t$, no nó de posição $e$;

$S_{\mathrm{t}, \mathrm{e}}=$ valor do ativo subjacente no nó correspondente ao período $t$, posição $e$.

$K=$ preço de exercício.

Figura 3. Rede binomial aditiva com combinações de v's e $\delta$ 's e alocação das probabilidades associadas

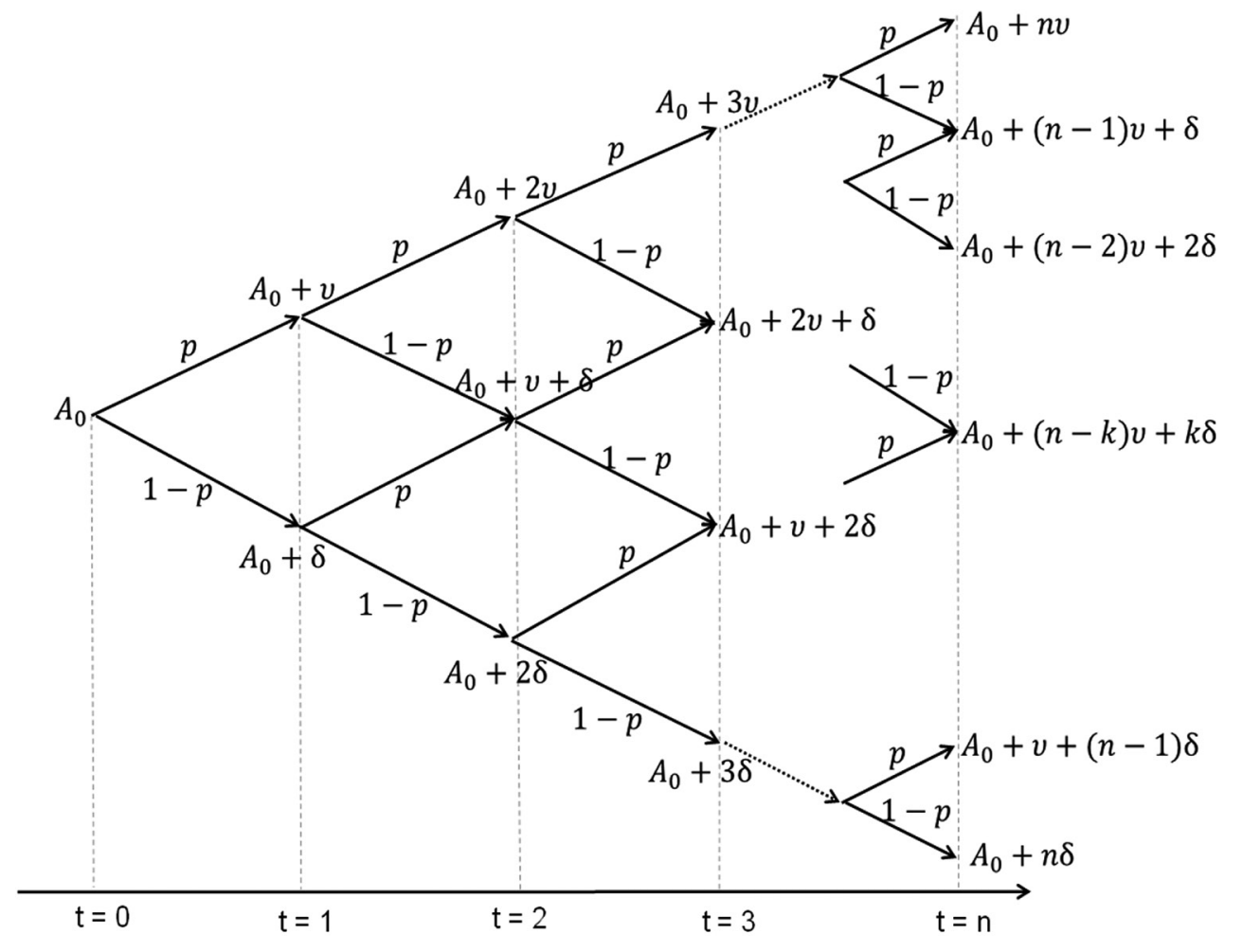

Fonte: Adaptado de Securato (2011). 
Em geral, o preço de exercício será o equivalente à execução do projeto, o qual será "comprado" pelo VPL previamente estimado via fluxo de caixa descontado. Ou seja, o VPL tradicionalmente calculado toma o lugar do preço de exercício no caso da TOR (COPELAND e TUFANO, 2004). Dessa forma, ter-se-á uma nova rede binomial para o valor das opções.

Entretanto, essa não é a resposta final em termos do valor da opção em $t=0$. O passo seguinte será, partindo de $t=n$, calcular qual o valor da opção do nó precedente $\left(t=n_{-1}\right)$, conforme a equação (7).

$$
\mathrm{O}_{\mathrm{t}=\mathrm{n}-1, \mathrm{e}}=\frac{\left\{\left[\mathrm{O}_{\mathrm{t}=\mathrm{n}, \mathrm{e} 1} \times \mathrm{p}\right]+\left[\mathrm{O}_{\mathrm{t}=\mathrm{n}, \mathrm{e} 2} \times(1-\mathrm{p})\right]\right\}}{\left(1+\mathrm{r}_{\mathrm{F}}\right)}
$$

Em que:

$\mathrm{r}_{\mathrm{F}}=$ taxa livre de risco do mercado.

No nó precedente, compara-se, então, o valor da opção obtido pela ponderação das opções do nó subsequente, descontado um período, com o valor da opção do mesmo nó, calculado conforme a equação (6). Para o passo seguinte, que será calcular o valor das opções nos nós em $t=n_{-2}$, será escolhido o valor máximo entre as equações (6) e (7) para que uma nova estimativa seja realizada, e assim sucessivamente, até que se chegue em $t=0$. Com base no VPL tradicionalmente estimado, obtido conforme a equação (1), e de posse do valor em $t=0$ da opção americana do respectivo projeto, obtém-se o chamado VPL expandido (VPL $\left.L_{\mathrm{EXP}}\right)$, que irá, conforme defende a TOR, refletir de forma mais adequada o valor financeiro do empreendimento (equação (8)).

$$
\mathrm{VPL}_{\mathrm{EXP}}=\mathrm{VPL}+\mathrm{O}_{0}
$$

Conforme cita Trigeorgis (1996), a expectativa é que $\mathrm{O}_{0}>0$, de forma que o VPL expandido assuma valores maiores (ou menos negativos, dependendo do caso) do que o VPL estimado tradicionalmente pelo método do fluxo de caixa descontado.

As estimativas dos parâmetros $u, d, p$ e $(1-p)$ necessários para o desenvolvimento do modelo binomial proposto foram definidas conforme Zilli (2010).

\subsection{Fontes dos dados, taxa de desconto e considerações complementares}

Os dados utilizados no presente estudo foram coletados junto às associações de produtores de cana-de-açúcar das cidades de Piracicaba (Associação dos Fornecedores de Cana de Piracicaba - Afocapi) e de Sertãozinho (Associação dos Plantadores de Cana do Oeste do Estado de São Paulo - Canaoeste); ao Pecege; ao Instituto de Economia Agrícola - IEA; ao Centro de Tecnologia Canavieira - CTC; à Orplana; à Unica; à Udop; e a usinas pertencentes às duas regiões analisadas.

A taxa de desconto considerada no presente estudo foi de $5,45 \%$, com base em estimativas obtidas a partir de:

a) Questionários aplicados a 39 agentes vinculados ao fornecimento de cana na região Centro-Sul, com taxa de juros real resultante de 5,07\% a.a.;

b) Razão entre os preços de arrendamento e do hectare de terra nas regiões em análise, segundo IEA (2013), com taxa real resultante de $4,69 \%$ a.a., e

c) Literatura pertinente consultada, tais como Zilio (2012), Paranhos e Paranhos (2010), Kaneko et al (2009), Zilli (2010), Alves et al (2008) e Pecege (2012), cujas taxas de juros reais variam entre $6 \%$ e $8 \%$ a.a.

A taxa de juros real livre de risco foi considerada conforme aponta Lima (2004) ${ }^{8}$. Neste sentido, utilizou-se a taxa de juros média relativa às Notas do Tesouro Nacional classe B (NTN-B) negociadas ao longo do primeiro semestre de 2013 com vencimento em 15/05/2045, com valor de $4,5 \%$ a.a.

Os fluxos de caixa foram projetados num horizonte de 30 anos. Em $t=30$ considerou-se

8. Para o autor, "a taxa de juro livre de risco deve ser aquela paga por um título governamental, cuja maturidade seja igual à vida útil da opção real de investir". 
uma perpetuidade baseada em um VUL modificado ${ }^{9}$, que foi estimado com base na equação 2 e a partir do VPL definido na equação 9.

$$
\mathrm{VPL}=\mathrm{C}_{\mathrm{i}}+\sum_{\mathrm{i}=6}^{29} \frac{\mathrm{C}_{\mathrm{i}}}{(1+\mathrm{r})^{\mathrm{i}}}
$$

\section{Resultados e discussões}

Os fluxos de caixa projetados para os projetos das regiões de Sertãozinho e Piracicaba caracterizaram-se como convencional e não convencional, respectivamente. No estudo da região de Piracicaba, cinco trocas de sinal ao longo do horizonte analisado foram constatadas, o que desqualifica análises a respeito da TIR do empreendimento. As estimativas dos indicadores de atratividade apontam para resultados análogos na comparação entre as duas regiões. No caso de Piracicaba, o VPL estimado para o projeto canavieiro foi de R\$62.472,38, com VUL de R \$ 4.274,73. Para o projeto de Sertãozinho o VPL foi estimado em $\mathrm{R} \$$ 664.930,14, com VUL de R\$ 45.498,44 e TIR de $6,64 \%$. Dessa forma, com base nas premissas adotadas, conclui-se que há indícios de viabilidade econômico-financeira no cultivo de cana-de-açúcar nas regióes em análise.

Procedendo-se à análise de identificação dos pontos de inflexão dos projetos analisados, foram variados individualmente os valores originais dos parâmetros preço do quilograma de ATR, produtividade agrícola, quantidade de ATR por tonelada de cana, preço de compra da terra e preço de arrendamento até que fosse alcançado um VPL $=0$. Os resultados são apresentados na Tabela 3 .

Sob a ótica do fluxo de caixa descontado, ambos os projetos apresentam atratividade econômica, embora esta se encontre próxima do limite entre a aceitação e rejeição do investimento. Sucessivas oscilações inesperadas nos patamares

9. A opção pelo recálculo do VPL e do VUL, considerando-se o intervalo de tempo entre o $6^{\circ}$ e o $29^{\circ}$ ano, se deu devido ao fato de que apenas em $\mathrm{t}=6$ o canavial estabiliza-se comercialmente, mantendo o padrão nos períodos subsequentes. de preços e quantidade de ATR e de produtividade agrícola afetam direta e significativamente a sustentação econômica dos fornecedores típicos das regiões de Piracicaba e Sertãozinho.

Na modelagem via TOR utilizou-se os VPLs estimados via fluxo de caixa descontado como proxy para os valores iniciais $\left(\mathrm{A}_{0}\right)$ considerados na análise binomial. A volatilidade considerada $\left(\sigma_{\mathrm{A}}\right)$ para o ativo subjacente foi estimada como sendo a média ponderada das volatilidades das variáveis produtividade agrícola, preço do ATR e quantidade de ATR por tonelada de cana ${ }^{10}$, uma vez que estes são os parâmetros que geram maior impacto sobre o VPL dentre os projetos analisados (Tabela 4).

Os fatores de aumento ou queda de $\mathrm{A}_{0}, \mathrm{v}$ e $\delta$, bem como suas respectivas probabilidades de ocorrência $(p$ e $(1-p))$, são apresentados na Tabela 5.

No caso do projeto de Piracicaba, estimou-se que as subidas de $A_{0}$ sejam caracterizadas por acréscimos fixos ( $v$ ) de $\mathrm{R} \$ 7.892,80$ e de decréscimos $(\delta)$ de - R\$7.007,47 de um para outro período de tempo. Já para Sertãozinho, $v$ foi estimado em $R \$ 90.202,84$ e $\delta$ em - R $\$ 79.427,85$.

Os valores das opções estimadas para os projetos de Piracicaba e Sertãozinho foram de $\mathrm{R} \$ 25.766,97$ e $\mathrm{R} \$ 277,628,39$, respectivamente. Somando-se a esses os valores dos VPLs calculados pelo método tradicional de análise de projetos, são obtidos VPLs expandidos de R $\$ 88.239,35$ para o projeto de Piracicaba e de R $942.558,53$ para Sertãozinho (Tabela 6). Em ambos os casos, as estimativas dos VPLs expandidos superam as dos VPLs calculados pelo método tradicional em mais de $40 \%$.

Complementarmente, tal como via método do fluxo de caixa descontado, foram calculados os pontos de inflexão $\left(\mathrm{VPL}_{\mathrm{EXP}}=0\right)$ considerando variações individuais dos parâmetros preço do ATR, produtividade agrícola, quantidade de ATR por tonelada de cana, preço de compra da terra

10. O peso atribuído às volatilidades de cada uma das variáveis foi definido pela razão entre o impacto individual de cada parâmetro sobre o VPL de cada projeto pelo somatório dos impactos das três variáveis sobre o VPL de cada projeto. 
e preço físico de arrendamento. Conforme esperado, quando se considera o valor das respectivas opções, os projetos canavieiros de Piracicaba e de Sertãozinho admitiriam patamares menores nos valores das variáveis preço e quantidade de ATR e produtividade agrícola antes de serem considerados financeiramente indiferentes. Respectivamente, tais parâmetros poderiam individualmente atingir valores de R $\$ 0,4296 / \mathrm{kg}$ ATR, 138,06 kg ATR/tc e 83,20 tc/ha (no caso de
Piracicaba) e de R $0,4071 / \mathrm{kg}$ ATR, 129,41 kg ATR/ tc e 78,37 tc/ha (no caso de Sertãozinho), quando, somente a partir de então, os projetos começariam a ser rejeitados pelo investidor. Na região de Piracicaba, o valor de inflexão para preço do hectare foi de $\mathrm{R} \$ 16,5$ mil, e para o preço físico de arrendamento, de 19,65 tc/ha. Já no projeto de Sertãozinho o preço limite para o hectare de terra foi de $\mathrm{R} \$ 26,1$ mil. O preço físico do arrendamento não influencia no VPL do projeto.

Tabela 3. Pontos de inflexão que tornam o VPL $=0$ nos projetos de Piracicaba e Sertãozinho: análise via método do fluxo de caixa descontado para variáveis selecionadas

\begin{tabular}{l|ccc|ccc}
\hline \multicolumn{1}{c}{ Variável } & \multicolumn{3}{c|}{ Piracicaba } & \multicolumn{3}{c}{ Sertãozinho } \\
\cline { 2 - 7 } & Original & VPL $=\mathbf{0}$ & $\mathbf{\Delta} \%$ & Original & VPL $=\mathbf{0}$ & $\mathbf{\Delta} \%$ \\
\hline Preço ATR (R\$/kg ATR) & 0,4365 & 0,4316 & $-1,1 \%$ & 0,4365 & 0,4158 & $-4,7 \%$ \\
Quantidade ATR (kg ATR/tc) & 140,10 & 138,66 & $-1,0 \%$ & 138,75 & 132,16 & $-4,7 \%$ \\
Produtividade (tc/ha) & 85,51 & 83,86 & $-1,9 \%$ & 86,99 & 80,72 & $-7,2 \%$ \\
Preço terra (R\$ mil/ha) & 14,2 & 15,8 & $11,3 \%$ & 20,1 & 24,3 & $20,9 \%$ \\
Preço arrendamento (tc/ha) & 16,70 & 18,82 & $12,7 \%$ & 27,43 & N/D & N/D \\
\hline
\end{tabular}

$\mathrm{N} / \mathrm{D}=\mathrm{O}$ parâmetro não gera impacto nos resultados do modelo.

Fonte: Dados da pesquisa.

Tabela 4. Valores das volatilidades dos parâmetros produtividade agrícola, preço do ATR e quantidade de ATR por tonelada de cana e volatilidade resultante considerada para o ativo subjacente

\begin{tabular}{l|cc|cc}
\hline \multicolumn{1}{c|}{ Parâmetro } & \multicolumn{2}{c|}{ Piracicaba } & \multicolumn{2}{c}{ Sertãozinho } \\
\cline { 2 - 5 } & Peso & $\sigma$ & \multicolumn{2}{c}{ Peso } \\
\hline Produtividade agrícola & $20 \%$ & $8,79 \%$ & $16 \%$ & $10,82 \%$ \\
Preço do ATR & $38 \%$ & $22,49 \%$ & $42 \%$ & $22,49 \%$ \\
Quantidade de ATR & $42 \%$ & $3,68 \%$ & $42 \%$ & $3,68 \%$ \\
Ativo subjacente $\left(\mathrm{A}_{0}\right)$ & & $11,9 \%$ & & $12,7 \%$ \\
\hline
\end{tabular}

Fonte: Dados da pesquisa.

Tabela 5. Valores de $v, \delta, p$ e $(1-p)$ considerados no modelo binomial aditivo

\begin{tabular}{lcccccc}
\hline \multicolumn{1}{c}{ Parâmetro } & $\mathbf{i}_{v}$ & $v$ & $\mathbf{i}_{\delta}$ & $\delta$ & $\mathbf{p}$ & $\mathbf{( 1 - p )}$ \\
\hline Piracicaba & $12,63 \%$ & 1,1263 & $-11,22 \%$ & 0,8878 & $66,33 \%$ & $33,67 \%$ \\
Sertãozinho & $13,57 \%$ & 1,1357 & $-11,95 \%$ & 0,8805 & $64,87 \%$ & $35,13 \%$ \\
\hline
\end{tabular}

Fonte: Dados da pesquisa.

Tabela 6. VPL, valor da opção e VPL expandido para os projetos de Piracicaba e Sertãozinho (em R\$)

\begin{tabular}{|c|c|c|c|c|}
\hline Projeto & $\begin{array}{l}\text { VPL } \\
\text { (1) }\end{array}$ & $\begin{array}{c}\text { Valor da opção } \\
\text { (2) }\end{array}$ & $\begin{array}{l}\text { VPL }_{\text {EXP }} \\
\text { (3) }\end{array}$ & $\begin{array}{c}\Delta \% \\
(3) /(1)\end{array}$ \\
\hline Piracicaba & $62.472,38$ & $25.766,97$ & $88.239,35$ & $41 \%$ \\
\hline Sertãozinho & $664.930,14$ & $277.628,39$ & $942.558,53$ & $42 \%$ \\
\hline
\end{tabular}

Fonte: Dados da pesquisa 
Visando extrapolar o universo das premissas adotadas originalmente - uma vez que, apesar de estas representarem convenientemente os típicos fornecedores de cana-de-açúcar das regiões de Piracicaba e Sertãozinho, existem inúmeras outras realidades produtivas em exercício nas mesmas localidades - procedeu-se para análises de cenários alternativos, os quais contemplaram:

a) a inexistência de incentivos sobre o CCT, até então mensurados em $26 \%$, para o fornecedor típico da região de Sertãozinho;

b) a produção canavieira sendo realizada em $100 \%$ de terras arrendadas em ambos os projetos analisados e

c) a produção canavieira sendo realizada em $100 \%$ de terras próprias no projeto da região de Piracicaba.

Os resultados obtidos são apresentados na Tabela 7. Ressalta-se que os cenários alternativos não foram analisados de forma combinada, ou seja, ou alternou-se apenas o parâmetro incentivo ao CCT, ou apenas o percentual de terras arrendadas, ou apenas o percentual de terras próprias.

O cenário a) aponta para uma inversão em relação à atratividade financeira da produção de cana-de-açúcar na região de Sertãozinho, haja vista que nem considerando o VPL expandido, obtido via TOR, houve indicação de viabilidade econômica. Entretanto, cabe ressaltar que a extinção dos incentivos dados pelas usinas aos fornecedores de cana-de-açúcar possivelmente tenderia a gerar um movimento de reequilíbrio nos preços das terras e arrendamentos. Isto por- que o atual status de produção provavelmente tem como precificado tal incentivo, e a não existência do mesmo teoricamente levaria o mercado a um novo ponto de equilíbrio. De forma semelhante, os resultados obtidos considerando as premissas do cenário b) indicam que não há viabilidade econômica nos empreendimentos analisados quando o cultivo da cana é realizado em terras $100 \%$ arrendadas. Infere-se, com base nesses indícios e levando-se em consideração as exposições apresentadas anteriormente, que o cultivo de cana-de-açúcar em terras próprias, nas condições pré-determinadas nos modelos em julgamento, se caracteriza como melhor alternativa para a atividade canavieira nas regiões contempladas no presente estudo. Tal conclusão torna-se de interesse particularmente quando se considera que o aumento da escala de produção surge como instrumento pertinente à redução dos custos fixos e aumento da atratividade comercial do fornecimento da cana-de-açúcar. Nesse sentido, deve-se notar os casos em que:

i) o aumento de escala advêm de ganhos de produtividade agrícola, sem a necessidade do respectivo aumento de área: Nessa situação, o desembolso unitário com arrendamentos, medido por tonelada de cana, cai, elevando automaticamente a atratividade financeira do empreendimento canavieiro;

ii) o aumento de escala advêm do aumento da área arrendada: Sob essa circunstância, vale analisar se o impacto financeiro positivo da redução dos outros custos

Tabela 7. Indicadores de atratividade para os projetos de Piracicaba e Sertãozinho com base nos cenários alternativos propostos: análises via fluxo de caixa descontado e via TOR

\begin{tabular}{lccc}
\hline \multicolumn{1}{c}{ Canário/região } & VPL (R\$) & VUL (R\$) & VPL $_{\text {EXP }}(\mathbf{R} \$)$ \\
\hline Cenário a) & & & $-413.143,12$ \\
$\quad$ Sertãozinho & $-709.295,30$ & $-48.534,16$ & $-21.595,16$ \\
\hline Cenário b) & & & $-278.959,30$ \\
$\quad$ Piracicaba & $-36.754,83$ & $-2.514,98$ & $205.100,34$ \\
$\quad$ Sertãozinho & $-478.924,88$ & $-32.770,86$ & \\
\hline Cenário c) & & $9.936,02$ & \\
$\quad$ Piracicaba & $145.208,52$ &
\end{tabular}

Fonte: Dados da pesquisa. 
fixos que não em arrendamentos supera o impacto financeiramente negativo do aumento dos desembolsos com aluguel de terras. Em caso positivo, ter-se-á elevação da atratividade econômica da atividade; em caso negativo, ter-se-á uma piora nos resultados dos VPLs e VPL $\mathrm{EXP}^{\text {P }}$

Para a verificação do item ii) procedeu-se à análise de sensibilidade do parâmetro produção de cana-de-açúcar, cujos valores originais dos projetos de Piracicaba e Sertãozinho são de 6.500 tc/safra e 15.000 tc/safra, respectivamente. Dada uma variação positiva de $1 \%$ sobre tais patamares, percebe-se que tanto $\frac{\partial \mathrm{VPL}}{\partial \text { producão }}>0$ quanto $\frac{\partial \mathrm{VPL}_{\mathrm{EXP}}}{\text { jproducão }}>0$ (Tabela 8), ou seja, há indícios de que o aumento de escala de produção em terras arrendadas trata, de fato, de uma ação pertinente na busca pela atratividade econômica para realidades cujos moldes se encaixam nos pressupostos então em análise. Tal efeito corrobora com aquele obtido no cenário base.

O cenário $c$ ), dentre as alternativas analisadas, apresentou os resultados mais otimistas (do ponto de vista do investidor) em relação à atratividade do projeto canavieiro piracicabano.

\section{Considerações finais}

Com base nas premissas adotadas no modelo proposto nesse estudo, conclui-se que há indícios de viabilidade econômica na atividade canavieira paulista, tomando como exemplos as realidades das regiões de Piracicaba e Sertãozinho. No primeiro cenário analisado, obteve-se estimativas positivas para os VPLs e VPLs expandidos em ambas as realidades, sendo os resultados obtidos via TOR, respectivamente, $41 \%$ e $42 \%$ superiores àqueles calculados via análise do fluxo de caixa descontado.

Tais indícios vão de encontro às conclusões conjuntas de Marques (2009), Xavier et al. (2009) e Pecege $(2010,2011,2012)$, as quais indicam que, em média, os custos unitários totais de produção não são cobertos pelos preços da cana-de-açúcar praticados no setor. Entretanto, vale salientar que existem diferenças em relação às premissas relativas aos incentivos sobre o desembolso com CCT, valores de remuneração da terra própria e taxas de juros consideradas nos respectivos modelos.

Por outro lado, os indícios apontados no cenário inicial corroboram com o disposto em Zilio (2012). Neste estudo, apesar da indicação pela inviabilidade do cultivo de cana-de-açúcar na região Tradicional (basicamente tratando-se do estado de São Paulo), haja vista o VPL negativo, nota-se que a TIR do projeto pertinente foi estimada em 5,89\%, acima da taxa mínima de atratividade assumida no modelo ora proposto. Assim, conclui-se que, sob premissas semelhantes, as inclinações para a viabilidade financeira são análogas em ambos os estudos.

Levando-se em consideração os valores das opções aferidos para os projetos de Piracicaba e Sertãozinho, bem como os valores dos VPLs tradicionalmente estimados, pôde-se analisar os pontos de inflexão de ambos os projetos, ou seja, os patamares médios de parâmetros selecionados

Tabela 8. Análise de sensibilidade para o parâmetro produção de cana-de-açúcar, para os projetos de Piracicaba e Sertãozinho, sob as premissas do cenário alternativo b): resultados via modelo do fluxo de caixa descontado e via TOR

\begin{tabular}{|c|c|c|c|c|c|c|}
\hline $\begin{array}{l}\text { Região } \\
\text { Variável }\end{array}$ & $\begin{array}{c}\text { Valor } \\
\text { Original } \\
\text { (tc) }\end{array}$ & $\begin{array}{c}\text { VPL } \\
\text { Original } \\
\text { (R\$ mil) }\end{array}$ & $\begin{array}{c}\text { VPL }_{\mathrm{EXP}} \\
\text { Original } \\
\text { (R\$ mil) }\end{array}$ & $\begin{array}{c}\text { Valor } \\
\Delta+1 \% \\
\text { (tc) } \\
\end{array}$ & $\begin{array}{c}\text { VPL } \\
\Delta+1 \% \\
\text { (R\$ mil) }\end{array}$ & $\begin{array}{c}\mathrm{VPL}_{\mathrm{EXP}} \\
\Delta+1 \% \\
\text { (R\$ mil) }\end{array}$ \\
\hline \multicolumn{7}{|l|}{ Piracicaba } \\
\hline Produção de cana & 6.500 & $-36,75$ & $-21,60$ & 6.565 & $-30,72$ & $-18,05$ \\
\hline \multicolumn{7}{|l|}{ Sertãozinho } \\
\hline Produção de cana & 15.000 & $-478,92$ & $-278,96$ & 15.150 & $-475,13$ & $-276,75$ \\
\hline
\end{tabular}

Fonte: Dados da pesquisa. 
dos modelos que, oscilando individualmente, fariam com que o VPL e o VPL $L_{\mathrm{EXP}}$ dos projetos retornassem valores nulos. Conforme esperado, concluiu-se que valores menores de preços do ATR, quantidade de ATR por tonelada de cana e produtividades agrícolas seriam admitidos nas análises via TOR, em comparação às estimativas via fluxo de caixa descontado. Por outro lado, via TOR, seriam maiores os patamares de preços de terras e arrendamentos admitidos pelos projetos avaliados.

Com o intuito de ultrapassar o horizonte dos resultados obtidos no cenário originalmente proposto, procedeu-se com a análise de três cenários alternativos, os quais buscaram atingir outras possibilidades de produção de cana-de-açúcar. Além de ter sido constatada inviabilidade financeira nos casos de inexistência de incentivos ao CCT na região de Sertãozinho e da produção unicamente em terras arrendadas (cenários $a$ ) e $b$ )), percebe-se que a produção em terras próprias, dadas as premissas admitidas, tende a gerar maior retorno para os empreendimentos analisados.

O aumento da escala de produção, conforme defendem autores como Kaneko et al. (2009), Zilio (2012) e Guedes et al. (2007), trata-se de alternativa pertinente para a redução de parte dos custos fixos de produção. Assim, conforme também exposto no presente estudo, a aquisição de terras - quando disponíveis - ou a expansão por meio de arrendamentos são ações que tendem a elevar o patamar de atratividade da atividade canavieira.

No que tange às principais variáveis de impacto sobre a atratividade da produção canavieira, destacam-se o fator extrínseco preço do ATR, ditado pelas relações de oferta e demanda de mercado; e os fatores intrínsecos quantidade de ATR por tonelada de cana e produtividade agrícola. A respeito desses dois últimos, percebe-se que ações focadas na maximização da qualidade da cana-de-açúcar entregue às usinas e no aumento da produtividade agrícola tendem a elevar significativamente a atratividade do investimento. No primeiro caso cita-se como pertinente o correto planejamento de safra, enquanto que no segundo deve-se atentar às políticas de maximi- zação de resultados de longo prazo, ou seja, ações que visem a manutenção sustentada da atividade ao longo dos ciclos de produção. A renovação sistemática dos canaviais, nesse quesito, é fundamental como objetivo de evitar quedas duradouras na produção por hectare dos canaviais. Ademais, a disseminação de políticas públicas como o Prorenova, do BNDES, tende a auxiliar o típico produtor de cana-de-açúcar no que diz respeito ao custo do capital empregado na atividade. Já o fator extrínseco preço - em relação ao qual o produtor rural é, em geral, tomador de valores - é uma questão que carece de decisões mais amplas (não setoriais) por parte, por exemplo, do governo brasileiro. Medidas mercadológico-tributárias, tais como aquelas constantes no manifesto de lançamento da Frente Parlamentar pela Valorização do Setor Sucroenergético (AFOCAPI, 2013), fazem parte das alternativas nas quais o Estado brasileiro poderia se sustentar para o aumento da competitividade do setor da cana-de-açúcar. Dentre as alternativas, destacam-se a "definição de uma política de precificação dos combustíveis" - algo que traria transparência ao mercado sucroenergético, uma vez que a relação de preços do etanol e da gasolina obedeceria a uma regra de conhecimento geral, e "a recuperação da função originária da CIDE [-Combustíveis, Contribuição de Intervenção no Domínio Econômico]" - cuja destinação, conforme rege a Lei no 10.336 de 19 de dezembro de 2001, dar-se-ia, inclusive, ao "pagamento de subsídios a preços ou transporte de álcool combustível (...)".

Por fim, conforme destacam Guedes et al. (2007 apud PERES, 2003), existem desafios significativos no que diz respeito à manutenção do homem no campo. Os autores citam, como justificativas vinculadas ao abandono da atividade rural, fatores como "desinteresse das novas gerações pela atividade agrícola, necessidade de buscar rendimentos fora da unidade agrícola, conflitos sobre a gestão do trabalho no interior, problemas de saúde e de idade do chefe da família". Se por um lado a participação histórica dos fornecedores de cana na produção total de cana moída foi reduzida - comparando-se informações de meados da 
década de 1980 (quando essa participação era de aproximadamente $35 \%$ ) com o início da década de 2010 (período cuja participação esteve próxima dos 25\%) - por outro, não se percebe redução de tal participação após meados dos anos 1990. Fatores como a valorização dos preços das terras e a redução do custo de capital são algumas das explicações para esse comportamento de manter-se na atividade, opção que possivelmente vem sendo exercida pelos fornecedores de cana-de-açúcar, inclusive aqueles atuantes em Piracicaba e Sertãozinho. Ainda, a replicação do estudo ora apresentado para regiões de expansão canavieira - como nos estados de Mato Grosso do Sul e Goiás - ou do Nordeste brasileiro seria útil para um melhor entendimento e tomada de decisão no âmbito do setor sucroenergéticos nacional.

\section{Referências}

AFOCAPI - Associação dos Fornecedores de Cana de Piracicaba. $27^{\circ}$ Informativo Semanal Departamento Técnico Agronômico AFOCAPI - semana 04/11/2013 à 08/11/2013. Disponível em <www.cana.com.br>. Acesso em 18 nov. 2013.

ALVES, L. R. A. et al. Viabilidade econômica da produção de algodão, soja e cana-de-açúcar no estado de Goiás. In: XLVI Congresso da Sociedade Brasileira de Economia, Administração e Sociologia Rural. Rio Branco, Acre. 20 a 23 de julho de 2008 .

BRASIL, H. G., ARONNE, A. e RAJÃO, A. Valuation of the options to verticalize and expand a carbonatite mine. Disponível em: <http://www.realoptions.org/ papers2011/ 73.pdf> . Acesso em 24 jan. 2012.

CELOTO, R. R. Apreçamento racional de projetos com flexibilidade e incertezas exógenas: uma aplicação em opções reais. 2004. 146p. Dissertação (Mestrado em Administração) - Faculdade de Economia, Administração e Contabilidade, Universidade de São Paulo, São Paulo, 2004.

CNA - Confederação da Agricultura e Pecuária do Brasil. Contribuição Sindical CNA 2012. Disponível em $<$ http://www.faec.org.br/Arquivos/CSR2012.pdf > . Acesso em: 12 mai. 2012.

COPELAND, T. E. e TUFANO, P. A Real-World Way to Manage Real Options. Harvard Business Review, Boston, v. 82, n. 3, p. 90-99, 2004.
CTC - Centro de Tecnologia Canavieira. Carta de solos. Disponível em: <www.ctcanavieira.com.br>. Piracicaba, 2012a.

Controle MUTUO. Disponível em: <www. ctcanavieira.com.br $>$. Piracicaba, 2012a.

DIXIT, A. K. e PINDYCK, R. S. Investment under uncertainty. New Jersey: Princeton University Press, 1994. $468 \mathrm{p}$.

GUEDES, S. N. R., TERCI, E. T. e PERES, M. T. M. $\mathrm{O}$ arrendamento como estratégia para enfrentar mudanças institucionais: um estudo com fornecedores de cana do estado de São Paulo. Organizações Rurais \& Agroindustriais, Lavras, v. 9, n. 2, p. 229-240, 2007.

IEA - Instituto de Economia Agrícola. Banco de dados. Disponível em: <http://www.iea.sp.gov.br/out/ bancodedados.html>. Acesso em: 14 mar. 2013a.

KANEKO, F. H. et al. Análise econômica da produção de cana-de-açúcar considerando-se a terceirização das operações agrícolas: o caso de um produtor. Pesquisa Agropecuária Tropical, Goiânia, v. 39, n. 3, p. 266-270, 2009.

KJÆRLAND, F. Areal analysis of investments in hydropower - the case of Norway. Energy Policy, Amsterdam, n. 35, p. 5901-5908, 2007.

KUMBAROĞLU, G., MADLENER, R. e DEMIREL, M. A real options evaluation model for the diffusion prospects of new renewable power generation technologies. Energy Economics, Amsterdam, n. 30, p. 1882-1908, 2006.

LIMA, G. A. C. Uma proposta de uso da teoria da preferência e das opções reais em projetos de exploração e produção de petróleo. 2004. 229p. Tese (Doutorado em Ciências) Instituto de Geociências, Universidade Estadual de Campinas, Campinas, 2004.

MADLENER, R., KUMBAROĞLU, G. e VOLKAN, Ş. E. Modeling technology adoption as an irreversible investment under uncertainty: the case of the Turkish electricity supply industry. Energy Economics, Amsterdam, n. 27, p. 139-163, 2005.

MARQUES, P. V. (Coord.). Custo de produção agrícola e industrial de açúcar e álcool no Brasil na safra 2007/2008. Piracicaba: Universidade de São Paulo, Escola Superior de Agricultura "Luiz de Queiroz", Programa de Educação Continuada em Economia e Gestão de Empresas/Departamento de Economia, Administração e Sociologia. 2009. 194 p. Relatório apresentado a Confederação da Agricultura e Pecuária do Brasil - CNA.

NEVES, M. F. Balanço do ano na cana mostra oportunidades desperdiçadas. Disponível em: <http://www.unica. 
com.br/opiniao/show.asp? $\mathrm{msgCode}=71884 \mathrm{~B} 7 \mathrm{E}-\mathrm{E} 32 \mathrm{C}-$ 419C-A2CE-F1CF234E0A5A> . Acesso em: 15 dez. 2011.

ORPLANA - Organização de Plantadores de Cana da Região Centro-Sul do Brasil. Circular. Disponível em: <http://www.orplana.com.br/novosite/circular. php?ano=2011>. Acesso em: 25 jan. 2012a.

. Perfil do produtor. Disponível em: <http://www. orplana.com.br/novosite/perfil.php $>$. Acesso em: 16 nov. 2012b.

PECEGE - Programa de Educação Continuada em Economia e Gestão de Empresas. Custos de produção de cana-de-açúcar, açúcar e etanol no Brasil: safra 2009/2010. Piracicaba, Universidade de São Paulo, Escola Superior de Agricultura "Luiz de Queiroz", Programa de Educação Continuada em Economia e Gestão de Empresas/Departamento de Economia, Administração e Sociologia. 2010. 100 p. Relatório apresentado a Confederação da Agricultura e Pecuária do Brasil - CNA.

. Custos de produção de cana-de-açúcar, açúcar e etanol no Brasil: fechamento da safra 2010/2011. Piracicaba, Universidade de São Paulo, Escola Superior de Agricultura "Luiz de Queiroz", Programa de Educação Continuada em Economia e Gestão de Empresas/ Departamento de Economia, Administração e Sociologia. 2011. 140 p. Relatório apresentado a Confederação da Agricultura e Pecuária do Brasil - CNA.

. Custos de produção de cana-de-açúcar, açúcar e etanol no Brasil: fechamento da safra 2011/2012. Piracicaba, Universidade de São Paulo, Escola Superior de Agricultura "Luiz de Queiroz", Programa de Educação Continuada em Economia e Gestão de Empresas/ Departamento de Economia, Administração e Sociologia. 2012. 50 p. Relatório apresentado a Confederação da Agricultura e Pecuária do Brasil - CNA.

PERINA, R. A. Gestão de custos e avaliação de investimentos no agronegócio. Piracicaba: Programa de Educação Continuada em Economia e Gestão de Empresas. 2007.

ROSS, S. A., WESTERFIELD, R. W. e JAFFE, J. F. Administração financeira: corporate finance. São Paulo: Atlas, 2007. 776 p.
SECURATO, J. R. O modelo binomial da estrutura de preços e a distribuição binomial de probabilidades. São Paulo: Universidade de São Paulo, 2011. Não paginado. Mimeografado.

TRIGEORGIS, L. Real options: managerial flexibility and strategy in resources allocation. Cambridge/ Massachusetts: The MIT Press, 1996. 435p.

UNICA - União da Indústria de Cana-de-Açúcar. Cenários e desafios para a expansão do setor sucroenergético. Disponível em: <http://www.unica.com.br/default. asp >. Acesso em: 12 mai. 2012.

Estimativa da safra 2011/2012. Disponível em: $\quad<$ http://www.unica.com.br/noticias/show. asp? nwsCode $=\{3$ FCCB84A-A408-434C-B54C23A290564A37\} > . Acesso em: 11 out. 2011.

UNICADATA - Produção. Disponível em: <http://www.unicadata.com.br/>. Acesso em: 17 ago. 2013.

UDOP - União dos Produtores de Bioenergia. Quantidade de cana entregue pelos fornecedores de cana e participação no total processado no Estado de São Paulo 1984/1985 a 2004/2005. Disponível em: <http://www. udop.com.br/index.php?item $=$ noticias\&cod $=14549>$. Acesso em: 26 fev. 2012.

XAVIER, C. E. O. et al. Custos de produção de canade-açúcar, açúcar e etanol no Brasil: safra 2008/2009. Piracicaba, Universidade de São Paulo, Escola Superior de Agricultura "Luiz de Queiroz", Programa de Educação Continuada em Economia e Gestão de Empresas/Departamento de Economia, Administração e Sociologia. 2009. 82 p. Relatório apresentado a Confederação da Agricultura e Pecuária do Brasil - CNA.

ZILIO, L. B. Viabilidade na produção de cana-deaçúcar no Centro-Sul brasileiro: o caso do fornecedor típico. AGRO em foco, Curitiba, ano I, n. 2, p. 76-82, 2012.

ZILLI, J. B. Valoração das propriedades rurais em Carazinho/ RS e Cascavel/PR: uma análise das opções reais. 2010. 147p. Tese (Doutorado em Economia Aplicada) Escola Superior de Agricultura "Luiz de Queiroz", Universidade de São Paulo, Piracicaba, 2010. 